\title{
Acute Effect of Citrulline Malate on Repetition Performance During Strength Training: A Systematic Review and Meta-Analysis
}

\author{
Fredrik Tonstad Vårvik and Thomas Bjørnsen \\ University of Agder
}

\author{
Adam M. Gonzalez \\ Hofstra University
}

\begin{abstract}
Citrulline malate (CitMal) is a dietary supplement that is suggested to enhance strength training performance. However, there is conflicting evidence on this matter. Thus, the purpose of this meta-analysis was to determine whether supplementing with CitMal prior to strength training could increase the total number of repetitions performed before reaching voluntary muscular failure. A systematic search was conducted wherein the inclusion criteria were double-blind, placebo-controlled studies in healthy participants that examined the effect of CitMal on repetitions to failure during upper body and lower body resistance exercises. The Hedges's $g$ standardized mean differences (SMD) between the placebo and CitMal trials were calculated and used in a random effect model. Two separate subanalyses were performed for upper body and lower body exercises. Eight studies, including 137 participants who consisted of strength-trained men $(n=101)$ and women $(n=26)$ in addition to untrained men $(n=9)$, fulfilled the inclusion criteria. Across the studies, 14 single-joint and multijoint exercises were performed with an average of $51 \pm 23$ total repetitions during $5 \pm 3$ sets per exercise at $\sim 70 \%$ of one-repetition maximum. Supplementing with 6-8 g of CitMal 40-60 min before exercise increased repetitions by $3 \pm 5(6.4 \pm 7.9 \%)$ compared with placebo $(p=.022)$ with a small SMD $(0.196)$. The subanalysis for the lower body resulted in a tendency for an effect of the supplement $(8.1 \pm 8.4 \%$, SMD: $0.27, p=.051)$ with no significant effect for the upper body $(5.7 \pm 8.4 \%$, SMD: $0.16, p=.131)$. The current analysis observed a small ergogenic effect of CitMal compared with placebo. Acute CitMal supplementation may, therefore, delay fatigue and enhance muscle endurance during high-intensity strength training.
\end{abstract}

Keywords: ergogenic aid, L-citrulline, sports supplementation

L-Citrulline, a nonessential amino acid found primarily in watermelon, has become an increasingly popular preworkout supplement due to its potential to increase $\mathrm{L}$-arginine bioavailability and promote nitric oxide (NO) production (Gonzalez \& Trexler, 2020). Although $\mathrm{L}$-citrulline is coproduced with $\mathrm{NO}$ via the $\mathrm{L}$-arginine-NO pathway, L-citrulline can also be recycled into L-arginine for subsequent NO generation (Figueroa et al., 2017). L-Citrulline supplementation increases plasma citrulline and plasma arginine concentrations in a dose-dependent fashion (Moinard et al., 2008), which promotes systemic availability of NO (Bahadoran et al., 2020). Moreover, compared with L-arginine supplementation, oral L-citrulline administration has been shown to be a more efficient means of elevating plasma L-arginine concentrations and NO bioactivity (Schwedhelm et al., 2008). NO regulates functions of skeletal muscle and blood vessels that may benefit exercise performance, such as promoting vasodilation, lowering the adenosine triphosphate (ATP) cost of cross-bridge cycling, and improving calcium handling in the sarcoplasmic reticulum (Campos et al., 2018; Stamler \& Meissner, 2001). In addition, L-citrulline is an essential component of the urea cycle in the liver and may facilitate ammonia buffering capabilities, improve aerobic utilization of pyruvate, and decrease lactate production (Rhim et al., 2020). Based on the aforementioned mechanisms, L-citrulline supplementation may improve muscle function and decrease muscle fatigue during high-intensity exercise.

Vårvik and Bjørnsen are with the Department of Sport Science and Physical Education, Faculty of Health and Sport Sciences, University of Agder, Kristiansand, Norway. Gonzalez is with the Department of Health Professions, Hofstra University, Hempstead, NY, USA. Vårvik (ftvaarvik@gmail.com) is corresponding author.
L-Citrulline is commonly supplemented in the form of citrulline malate (CitMal) wherein malic acid is combined with L-citrulline. Malate is a tricarboxylic acid cycle intermediate that has been proposed to increase oxidative ATP production (Bendahan et al., 2002). However, malate's potential performance-enhancing effects have not been adequately investigated. Nevertheless, several studies have investigated the ergogenic potential of CitMal supplementation on both aerobic and anaerobic exercise performance (Gonzalez $\&$ Trexler, 2020). Due to its potential to delay fatigue during highintensity exercise, studies have specifically investigated the acute effects of CitMal supplementation on strength, power, and resistance training performance (Chappell et al., 2018a, 2018b; Cunniffe et al., 2016; Cutrufello et al., 2015; da Silva et al., 2017; Farney et al., 2017; Glenn et al., 2015, 2016; Gonzalez et al., 2017; Martínez-Sánchez et al., 2017; Pérez-Guisado \& Jakeman, 2010; Trexler et al., 2019a; Wax et al., 2015a, 2015b). Although these studies have offered mixed findings, some have shown that acute CitMal supplementation may increase performance during highintensity strength and power tasks.

The majority of the research pertaining to strength training has investigated the acute effect of CitMal supplementation on repetitions to failure during single-joint and/or multijoint exercise protocols. Here, several of the studies have demonstrated that subjects who consume a single dose of CitMal (6-8 g) experience less fatigue to the working muscles compared with a placebo groupallowing them to perform more repetitions to failure (Pérez-Guisado \& Jakeman, 2010; Wax et al., 2015a, 2015b). However, not all studies have shown such favorable results (Chappell et al., 2018a, 2018b; da Silva et al., 2017; Gonzalez et al., 2017). Recently, a published meta-analysis has indicated a small beneficial effect of CitMal supplementation on high-intensity strength and power 
performance; however, the analysis included several different strength and power variables from resistance training and sprinting performance tests involving large muscle groups (Trexler et al., 2019b). Therefore, conclusions on CitMal's effect on acute muscle endurance performance during strength training are lacking. The ability of CitMal to augment muscle endurance during strength training may be practically meaningful for individuals interested in performing more repetitions and increasing total training volume within an exercise bout. Thus, the main purpose of this study was to conduct a meta-analysis of the double-blind, placebo-controlled trials investigating the acute effects of CitMal supplementation on repetition performance during strength training in healthy adults. In addition, the muscles of the lower body have a larger volume than muscles of the upper body (Holzbaur et al., 2007; Lube et al., 2016), which may require greater blood flow and energy production (Calbet et al., 2007). Therefore, a subanalysis was conducted to investigate whether a potential effect of CitMal would be more pronounced during lower body versus upper body exercises.

\section{Methods}

A systematic review and meta-analysis was conducted and reported in accordance with the PRISMA guidelines (Moher et al., 2009). Assessment of the methodological quality of the included studies was conducted using the "Tool for the assessment of study quality and reporting in exercise" (TESTEX), a validated 15-item score system for exercise training studies (Smart et al., 2015). The checklist is designed to assess study quality (Items 1-5) and study reporting (Items 6-12), where higher scores represent higher methodological quality. However, points 6C (exercise attendance), 7 (intention to treat analysis), 10 (activity monitoring in control groups), and 11 (progressive program) in the study reporting section were omitted as they were not deemed relevant for the acute study designs included in this article. Thus, 11 points were used as the maximum score instead of 15. The assessment was performed by the lead author. If any points were unclear, they were discussed and solved with consensus by all authors. Based on the sum of the scores, we modified and classified 9-11 points as high quality, 6-8 points as good quality, and $\leq 5$ points as low quality (Nunes et al., 2020). Furthermore, we considered the protocol to not fulfill the requirements for preregistration at Prospero.

\section{Search Strategy}

Literature searches of the MEDLINE and SPORTDiscus databases were performed through EBSCOhost with a combination of the following MeSH terms and keywords. MeSH: Citrulline or Malates and Exercise or Muscles or "Muscle, Skeletal" or "Resistance training" or "Weight Lifting" or "Muscle strength." Keywords: "citrulline malate" and "resistance (training or exercise)" or "strength (training or exercise)," and "performance or repetitions or capacity or failure or fatigue." Included studies had to be classified as "randomized controlled trial" or "controlled clinical trial" and not be a review or meta-analysis. The search was performed in March, 2020 and was completed by F.T. Vårvik.

\section{Inclusion Criteria}

Potential studies for the analysis were required to meet the following criteria:

(a) An experimental peer-reviewed study published in English

(b) A double-blind randomized controlled design (c) Used healthy humans as participants

(d) Assessed the effect of supplementing with CitMal compared with placebo on repetitions to failure during strength training

(e) Strength training included single-joint and/or multijoint dynamic exercises

Studies were excluded if the CitMal supplement was combined with other ergogenic ingredients (e.g., caffeine, creatine, betaalanine, etc.) or if they did not meet the aforementioned criteria.

\section{Study Selection and Data Extraction}

Titles and abstracts of the initially identified studies were first screened independently by two of the authors (F.T. Vårvik and A.M. Gonzalez) based on the inclusion and exclusion criteria. The two authors (F.T. Vårvik and A.M. Gonzalez) reviewed full texts if necessary to determine whether the studies were eligible to be included in the analysis. Any disagreement between authors was resolved through discussion and agreement. Reference lists of the included articles were screened for addition papers, and subsequent data extraction was performed independently by two of the authors (T. Bjørnsen and F.T. Vårvik). Data extraction included study design, total repetitions (mean and $S D$ ), sample size, participant characteristics (age, sex, and training status), and supplement details in addition to resistance exercise(s) and exercise protocols. All extracted data were written in Microsoft Excel Spreadsheets (Microsoft Corporation [2019]; Microsoft Excel, https://office. microsoft.com/excel). When required data were not reported, the authors of the articles were contacted directly with a request for additional data. If requested data were not obtained, we estimated values using a web-based tool to extract numerical data from graph images. Briefly, two endpoints on both the $X$ and $Y$ axis were first chosen before entering the identical reference values from the figures, followed by manually selecting the mean and $S D$ with the software WebPlotDigitizer (version 4.1; https://automeris.io/ WebPlotDigitizer/). If total repetitions and SDs were not reported, the sum of the repetitions for all sets was calculated in addition to the variance from the $S D$ of each set wherein the sum of the variance was used to calculate the $S D$ for total repetitions.

\section{Statistical Analysis}

Standardized mean differences and 95\% confidence intervals (CIs) were calculated between the placebo and CitMal trials based on the sample size, means, and SDs of the total number of repetitions and the correlation between the conditions. To minimize bias and, thus, account for the possible overestimation from studies with small sample sizes, the correction-based Hedges's $g$ was used as SMD (Borenstein, 2009). Correlation between conditions was computed with the following formula (Equation 1):

$$
\frac{\text { Mean difference }}{[\text { pooled } S D \text { change } / \sqrt{(2(1-r)}]} \text {, }
$$

where pooled change $S D$ was calculated using the correlation coefficient. As none of the included studies reported correlation coefficient $(r)$ and the model used for the analysis requires it, we calculated the average correlation from the data in a previous study by one of the authors (Gonzalez et al., 2017), and the estimated correlations from the other studies were determined with the following formula (Equation 2): 


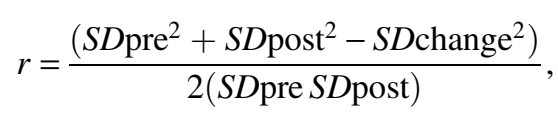

$S D$ pre and $S D$ post are the $S D$ s for the pre- and posttest means, respectively; $S D$ change is the $S D$ of the change scores (Higgins \& Green, 2009). When SDchange was not reported, the $p$ value for the pre-post difference was used to estimate it. If a threshold for significance was reported rather than a specific value (i.e., $p<.001$ ), the threshold value was used in the formula. Both procedures are explained in detail in the Cochrane Handbook for Systematic Reviews of Interventions (Higgins \& Green, 2009). The average correlation across the studies was $r=.72$, which was used in the current analysis. For the meta-analysis, the software Comprehensive Meta-analysis (version 3.3; Biostat Inc., Englewood, NJ) was used, and a random effect model was chosen for all analyses. Whenever a study had tested more than one exercise, all exercises were included separately, but the variance was multiplied by the total number of exercises so that the total weighting of the study was similar to a single aggregated effect size (Borenstein et al., 2009). In addition, when SDs for the total number of repetitions were not reported, we used each set's $S D$ to calculate the variance $\left(S D^{2}=\sigma^{2}\right)$ and then the square root of the summed variance as the $S D$ value for the analysis. Furthermore, the study by da Silva et al. (2017) had participants perform one set of repetitions to failure on three consecutive days as opposed to within a single exercise bout. Therefore, we used the sum of all repetitions performed for all 3 days combined in the analysis. Moreover, in Chappell et al. (2018b), the SDs of only Set 1 and Set 10 were reported in the text, whereas all sets were presented in a figure. However, the values reported in this study appeared to be higher than the values in the figure. Therefore, we chose the highest values to be certain to take into account the highest possible variability. Consequently, the average $S D$ s between Set 1 and Set 10 were used for Sets 2-9 before calculating the total repetitions SDs with the aforementioned method. In addition, sensitivity analyses were performed to test whether the potential results were robust and to identify whether any studies had a large impact on the results by removing one study at a time from the analysis. Studies were considered influential if the removal resulted in a large change in the SMD or significance level. Subanalyses were performed for upper body exercises and for lower body exercises wherein the variance was also adjusted within the subanalysis based on total number of tested exercises from the same study. However, Glenn et al. (2016) was the only study that included one exercise each for the upper body and lower body; therefore, the variance was not adjusted as it was two separate analyses. Weightedpercentage differences and weighted number of repetitions with the respective $S D$ s for performance between CitMal and placebo conditions were also calculated using the same study weighting as the metaanalysis. Assessment of heterogeneity and variance were conducted with Cochran's $Q$ test, $I^{2}$, and $T^{2}$. Publication biases were tested with Egger's regression test, and potential funnel plot asymmetry was further assessed with the Duval and Tweedie's trim and fill method. The following SMD classifications of magnitude were used: small $(\leq 0.2)$, medium (0.2-0.5), large (0.5-0.8), and very large ( $>0.8$; Cohen, 1988). An alpha level of $p \leq .05$ was set as the criterion for statistical significance, and results are reported as mean $\pm 95 \%$ CIs or $S D$ s.

\section{Results}

\section{Literature Search and Study Characteristics}

The literature search resulted in 84 potential studies after removal of duplicates (Figure 1). Following screening, a total of eight studies met the inclusion criteria (Chappell et al., 2018a, 2018b;

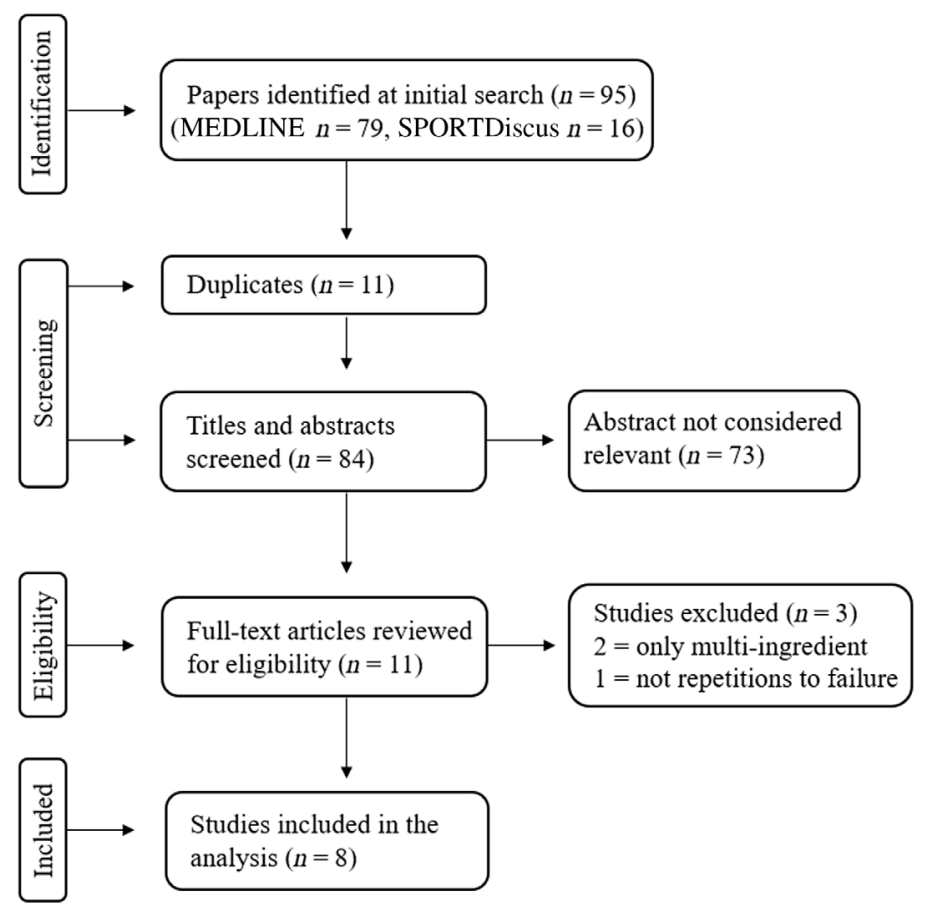

Figure 1 - Prisma flow chart.

da Silva et al., 2017; Glenn et al., 2015; Gonzalez et al., 2017; Pérez-Guisado \& Jakeman, 2010; Wax et al., 2015a, 2015b). There were a total of 137 participants (26 females) with an age of $25.4 \pm 5.4$ (mean $\pm S D$ ) years old. All except nine men (da Silva et al., 2017) had $\geq 6$ months of strength training experience. The majority of the studies employed a high load of $60-80 \%$ of one-repetition maximum, whereas one study used the participant's own body weight as resistance (Wax et al., 2015a). Across studies, 14 different single-joint and multijoint exercises, consisting of seven upper body ( $n=101$ participants) and seven lower body exercises ( $n=51$ participants), were employed. Participants performed 3-10 $(5 \pm 3)$ sets to voluntary failure, on average, which resulted in $51 \pm 23$ total repetitions for each exercise. The dosage of CitMal supplementation ranged from $6 \mathrm{~g}$ (da Silva et al., 2017) to 8 g (Chappell et al., 2018a, 2018b; Glenn et al., 2015; Gonzalez et al., 2017; Pérez-Guisado \& Jakeman, 2010; Wax et al., 2015a, 2015b) and was ingested $40 \mathrm{~min}$ (Gonzalez et al., 2017) or $60 \mathrm{~min}$ preexercise (Chappell et al., 2018a, 2018b; da Silva et al., 2017; Glenn et al., 2015; Pérez-Guisado \& Jakeman, 2010; Wax et al., 2015a, 2015b). To control for diet, all studies instructed participants to duplicate the nutritional intake prior to each experimental trial. However, trials were performed both in an overnight fasted state (Chappell et al., 2018b; Gonzalez et al., 2017) or a fed state (Chappell et al., 2018a; Glenn et al., 2016), or the state was not specified (da Silva et al., 2017; Pérez-Guisado \& Jakeman, 2010; Wax et al., 2015a, 2015b). A detailed description of participants, study design, and results is provided in Table 1.

\section{Quality Assessment}

The mean quality rating score was $10 \pm 1$ out of a possible score of 11 points (Table 2), and all included studies were rated as having high methodological quality (Chappell et al., 2018a, 2018b; da Silva et al., 2017; Glenn et al., 2015; Gonzalez et al., 2017; PérezGuisado \& Jakeman, 2010; Wax et al., 2015a, 2015b). However, 


\begin{tabular}{|c|c|c|c|c|c|c|}
\hline \multirow[b]{2}{*}{ Study } & \multicolumn{3}{|c|}{ Participants } & \multirow[b]{2}{*}{$\begin{array}{c}\text { Supplement } \\
\text { (preexercise) }\end{array}$} & \multirow[b]{2}{*}{ Testing protocol } & \multirow[b]{2}{*}{$\begin{array}{l}\text { Total repetitions } \\
\text { performed }\end{array}$} \\
\hline & Sex & $\begin{array}{c}\text { Age } \\
(\text { mean } \pm S D) \\
\text { years }\end{array}$ & $\begin{array}{l}\text { Training } \\
\text { status }\end{array}$ & & & \\
\hline $\begin{array}{l}\text { Chappell et al. } \\
\text { (2018a) }\end{array}$ & $\begin{array}{l}11 \mathrm{M} \\
\text { and } 4 \mathrm{~F}\end{array}$ & $23.7 \pm 2.4$ & $\begin{array}{l}\text { Strength } \\
\text { trained }\end{array}$ & $\begin{array}{l}8 \text { g CitMal } \\
(60 \mathrm{~min})\end{array}$ & $\begin{array}{l}10 \text { sets knee extensions; } \\
80 \% \text { 1RM, 1-min RI }\end{array}$ & $\begin{array}{l}\leftrightarrow \text { Knee extensions } \\
\text { (CitMal: 90.9, PL: } 94.9 \text { ) }\end{array}$ \\
\hline $\begin{array}{l}\text { Chappell et al. } \\
\text { (2018b) }\end{array}$ & $\begin{array}{c}12 \mathrm{M} \\
\text { and } 7 \mathrm{~F}\end{array}$ & $25.7 \pm 7.7$ & $\begin{array}{l}\text { Strength } \\
\text { trained }\end{array}$ & $\begin{array}{l}8 \underset{\text { g CitMal }}{(60 \mathrm{~min})} \\
\end{array}$ & $\begin{array}{l}10 \text { sets barbell curls; } \\
80 \% \text { 1RM, 1-min RI }\end{array}$ & $\begin{array}{l}\leftrightarrow \text { Barbell curls } \\
\text { (CitMal: 61.8, PL: 63.0) }\end{array}$ \\
\hline $\begin{array}{l}\text { da Silva et al. } \\
\text { (2017) }\end{array}$ & $9 \mathrm{M}$ & $24.0 \pm 3.3$ & Untrained & $\begin{array}{l}6 \mathrm{~g} \mathrm{CitMal} \\
(60 \mathrm{~min})\end{array}$ & $\begin{array}{l}3 \text { days of } 1 \text { set leg press } \\
\text { and hack squat; 10RM, } \\
\text { 2-min RI }\end{array}$ & $\begin{array}{l}\leftrightarrow \text { Leg press } \\
\text { (CitMal: 35.9, PL: 33.0) } \\
\leftrightarrow \text { Hack squat } \\
\text { (CitMal: 35.0, PL: 32.8) }\end{array}$ \\
\hline $\begin{array}{l}\text { Glenn et al. } \\
(2015)\end{array}$ & $15 \mathrm{~F}$ & $23.0 \pm 3.0$ & $\begin{array}{l}\text { Strength } \\
\text { trained }\end{array}$ & $\begin{array}{l}8 \underset{\text { g CitMal }}{(60 \mathrm{~min})} \\
\end{array}$ & $\begin{array}{l}6 \text { sets each of bench press } \\
\text { and leg press; } 80 \% 1 \mathrm{RM}, \\
1 \text {-min RI }\end{array}$ & $\begin{array}{l}\uparrow \text { Bench press } \\
\text { (CitMal: 34.1, PL: 32.9) } \\
\uparrow \text { Leg press } \\
\text { (CitMal: 66.7.1, PL: } 55.1 \text { ) }\end{array}$ \\
\hline $\begin{array}{l}\text { Gonzalez et al. } \\
\text { (2017) }\end{array}$ & $12 \mathrm{M}$ & $21.4 \pm 1.6$ & $\begin{array}{l}\text { Strength } \\
\text { trained }\end{array}$ & $\begin{array}{l}8 \text { g CitMal } \\
(40 \mathrm{~min})\end{array}$ & $\begin{array}{l}5 \text { sets bench press; } \\
75 \% \text { 1RM, 2-min RI }\end{array}$ & $\begin{array}{l}\leftrightarrow \text { Bench press } \\
\text { (CitMal: 35.3, PL: 35.8) }\end{array}$ \\
\hline $\begin{array}{l}\text { Pérez-Guisado } \\
\text { and Jakeman } \\
\text { (2010) }\end{array}$ & $41 \mathrm{M}$ & $29.8 \pm 7.6$ & $\begin{array}{l}\text { Strength } \\
\text { trained }\end{array}$ & $\begin{array}{l}8 \mathrm{~g} \mathrm{CitMal} \\
(60 \mathrm{~min})\end{array}$ & $\begin{array}{l}8 \text { sets bench press; } \\
80 \% 1 \mathrm{RM}, 1-\mathrm{min} \mathrm{RI}\end{array}$ & $\begin{array}{l}\uparrow \text { Bench press } \\
\text { (CitMal: } 68.4, \text { PL: } 60.1 \text { ) }\end{array}$ \\
\hline $\begin{array}{l}\text { Wax et al. } \\
(2015 \mathrm{a})\end{array}$ & $14 \mathrm{M}$ & $23.5 \pm 1.5$ & $\begin{array}{l}\text { Strength } \\
\text { trained }\end{array}$ & $\begin{array}{l}8 \underset{\text { g CitMal }}{(60 \mathrm{~min})} \\
\end{array}$ & $\begin{array}{l}3 \text { sets each of chin-ups, } \\
\text { reverse chin-ups, and } \\
\text { push-ups; BW, 3-min RI }\end{array}$ & $\begin{array}{l}\uparrow \text { Chin-ups } \\
\text { (CitMal: } 32.2 \text {, PL: 28.4) } \\
\uparrow \text { Reverse chin-ups } \\
\text { (CitMal: 32.1, PL: 26.6) } \\
\uparrow \text { Push-ups } \\
\text { (CitMal: 97.7, PL: } 89.1 \text { ) }\end{array}$ \\
\hline $\begin{array}{l}\text { Wax et al. } \\
(2015 b)\end{array}$ & $12 \mathrm{M}$ & $22.1 \pm 1.4$ & $\begin{array}{l}\text { Strength } \\
\text { trained }\end{array}$ & $\begin{array}{l}8 \underset{\text { g CitMal }}{(60 \mathrm{~min})} \\
\end{array}$ & $\begin{array}{l}5 \text { sets each of leg press, } \\
\text { hack squat, and knee } \\
\text { extensions; } 60 \% 1 \mathrm{RM} \text {, } \\
\text { 3-min RI }\end{array}$ & $\begin{array}{l}\uparrow \text { Leg press } \\
\text { (CitMal: } 75.8 \text {, PL: } 72.0 \text { ) } \\
\uparrow \text { Hack squat } \\
\text { (CitMal: 38.3, PL: } 31.7 \text { ) } \\
\uparrow \text { Knee extensions } \\
\text { (CitMal: 38.2, PL: } 36.0 \text { ) }\end{array}$ \\
\hline
\end{tabular}

Note. $\mathrm{M}=$ male; $\mathrm{F}=$ female; $\mathrm{CitMal}=$ citrulline malate; $\mathrm{RM}=$ repetition maximum; $\mathrm{RI}=$ rest intervals; $\mathrm{PL}=$ placebo; $\mathrm{BW}=$ bodyweight; $\leftrightarrow=$ no significant difference compared with placebo; $\uparrow=$ significantly greater repetitions with CitMal than placebo $(p<.05)$.

Table 2 Study Methodological Quality Scores Based on the TESTEX Criteria

\begin{tabular}{|c|c|c|c|c|c|c|c|c|c|}
\hline Criteria & $\begin{array}{c}\text { Chappell } \\
\text { et al. } \\
(2018 a) \\
\end{array}$ & $\begin{array}{c}\text { Chappell } \\
\text { et al. } \\
(2018 b) \\
\end{array}$ & $\begin{array}{c}\text { da } \\
\text { Silva } \\
\text { et al. } \\
(2017) \\
\end{array}$ & $\begin{array}{l}\text { Glenn } \\
\text { et al. } \\
(2015)\end{array}$ & $\begin{array}{c}\text { Gonzalez } \\
\text { et al. } \\
(2017) \\
\end{array}$ & $\begin{array}{l}\text { Pérez- } \\
\text { Guisado } \\
\text { and } \\
\text { Jakeman } \\
\text { (2010) }\end{array}$ & $\begin{array}{c}\text { Wax } \\
\text { et al. } \\
(2015 b)\end{array}$ & $\begin{array}{c}\text { Wax } \\
\text { et al. } \\
(2015 a)\end{array}$ & $\begin{array}{c}\text { Sum } \\
\text { (maximum } \\
8 \text { 8) }\end{array}$ \\
\hline \multicolumn{10}{|l|}{ Study quality } \\
\hline 1. Eligibility criteria specified & 1 & 1 & 1 & 1 & 1 & 1 & 1 & 1 & 8 \\
\hline 2. Randomization method & 1 & 1 & 0 & 0 & 0 & 0 & 0 & 0 & 2 \\
\hline 3. Allocation concealed & 1 & 1 & 1 & 1 & 1 & 1 & 1 & 1 & 8 \\
\hline 4. No baseline differences & 1 & 1 & 1 & 1 & 1 & 1 & 1 & 1 & 8 \\
\hline 5. Blinding of assessors & 1 & 1 & 1 & 1 & 1 & 1 & 1 & 1 & 8 \\
\hline \multicolumn{10}{|l|}{ Study reporting } \\
\hline 6a. Compliance $>85 \%$ & 0 & 1 & 1 & 1 & 1 & 1 & 1 & 1 & 7 \\
\hline 6b. Adverse events & 1 & 0 & 1 & 1 & 0 & 1 & 1 & 0 & 5 \\
\hline 8a. Between group analysis & 1 & 1 & 1 & 1 & 1 & 1 & 1 & 1 & 8 \\
\hline 8b. 8 a for secondary outcomes & 1 & 1 & 1 & 1 & 1 & 1 & 1 & 1 & 8 \\
\hline 9. Point estimates and variability & 1 & 1 & 1 & 1 & 1 & 1 & 1 & 1 & 8 \\
\hline $\begin{array}{l}\text { 12. Exercise volume and energy } \\
\text { expenditure can be calculated }\end{array}$ & 1 & 1 & 1 & 1 & 1 & 1 & 1 & 1 & 8 \\
\hline Sum (maximum 11) & 10 & 10 & 10 & 10 & 9 & 10 & 10 & 9 & \\
\hline
\end{tabular}

Note. Points $6 \mathrm{c}, 7,10$, and 11 were not included. TESTEX $=$ tool for the assessment of study quality and reporting in exercise. 
three studies did not report about potential side effects after supplementation (Chappell et al., 2018b; Gonzalez et al., 2017; Wax et al., 2015a). Although only two studies reported method of randomization (Chappell et al., 2018a, 2018b), all the included studies were double-blind, placebo-controlled crossover designs. In addition, all studies except one (Pérez-Guisado \& Jakeman, 2010) specified that a counterbalanced method was applied.

\section{Meta-Analysis: Effects of CitMal Supplementation on Repetitions to Failure}

The main meta-analysis resulted in an increase of $3 \pm 5$ weighted repetitions in the CitMal condition compared with the placebo condition with a Hedges's $g$ SMD of 0.196 (95\% CI [0.029, 0.364]) and a weighted percentage difference of $6.4 \pm 7.9 \%(p=.022)$. The forest plot of the analysis is presented in Figure 2. Sensitivity analysis (removing one study at a time) revealed that the results were moderately robust, but removal of the study by Pérez-Guisado and Jakeman (2010) would have adjusted the point estimate from a significant effect to a tendency ( $p=.052$, SMD: 0.189). However, removing any one of the three studies wherein the point estimate crossed toward a negative effect (Chappell et al., 2018a, 2018b; Gonzalez et al., 2017) would have increased the SMD by approximately 0.03-0.04 in favor of CitMal.

\section{Subanalysis}

Subanalysis for the lower body revealed a tendency for an effect of supplementing with CitMal on repetitions to failure with an SMD of 0.266 (95\% CI $[-0.001,0.533], p=.051)$ and a weighted percentage difference of $8.1 \pm 8.4 \%$ in comparison with the placebo conditions (Figure 3). No effect was observed for the upper body analysis (SMD: $0.166,95 \%$ CI $[-0.050,0.382]$ and $5.7 \pm 8.4 \%$, $p=.131$ ). Sensitivity analysis revealed that removal of any study except the Chappell et al. (2018a, 2018b) studies would adjust the point estimate toward the null and increase the $p$ value, whereas removal of the Chappell et al. (2018a, 2018b) studies would result in significant SMD for both analyses.

\section{Risk of Bias and Heterogeneity}

Eggers test for funnel plot asymmetry yielded a tendency (regression intercept $=1.45, p=.086$ ) indicating potential publication bias, but this was not supported by visual inspection. However, the Duval and Tweedie's trim and fill analysis method observed four missing studies to the left of the funnel plot and adjusted the SMD from 0.196 to a nonsignificant SMD of 0.104 [ -0.017 , 0.216]. In addition, Cochran's $Q$ test for heterogeneity revealed a tendency $\left(Q=19.98, p=.096, I^{2}=34.92\right.$, and $\left.T^{2}=.03\right)$ indicating potential between-study variance across the included studies.

\section{Discussion}

The objective of this meta-analysis was to examine the acute effect of CitMal supplementation on repetitions to failure during strength training. Eight studies consisting of 14 strength exercises met the inclusion criteria with a total sample size of 137 participants. The main findings were that supplementing with CitMal before strength training significantly increased repetitions to failure by three repetitions $(6.4 \%)$, corresponding to a small Hedges's $g$ SMD of 0.196 (95\% CI $[0.029,0.364])$. Subanalysis of lower body exercises showed a tendency for a positive effect with CitMal ( $p=.051$, SMD: 0.266; $[-0.0009,0.534])$, whereas the upper body analysis revealed no significant effect of the supplement $(p=.131$, SMD: 0.166; $[-0.050,0.382])$. Although the effect size is small, CitMal supplementation may meaningfully increase training volume by enhancing muscle endurance during high-intensity performance.

CitMal is one of the most common ingredients found in multiingredient preworkout supplements (Jagim et al., 2019), yet CitMal was not included in the latest International Olympic Committee consensus statement on recommended dietary supplements for athletes (Maughan et al., 2018). However, in a recent review by Trexler et al. (2019b), CitMal was reported to offer beneficial effects on a variety of strength performance measurements with a small effect size of 0.20 . These findings are in line with the result of the current meta-analysis. CitMal's magnitude of effect appears to be slightly lower than effects observed for other ergogenic
Study

Chappell et al. (2018a)

Chappell et al. (2018b)

da Silva et al. (2017)

da Silva et al. (2017)

Glenn et al. (2015)

Glenn et al. (2015)

Gonzalez et al. (2017)

Pérez-Guisado and Jakeman (2010)

Wax et al. (2015a)

Wax et al. (2015a)

Wax et al. (2015a)

Wax et al. (2015b)

Wax et al. (2015b)

Wax et al. (2015b)
Exercise

Barbell biceps curls
Knee extension
Hack squat
Leg press
Bench press
Leg press
Bench press
Bench press
Chin-ups
Push-ups
Reverse chin-ups
Hack squat
Knee extension
Leg press

\begin{tabular}{ccc}
\multicolumn{3}{c}{ Statistics for each study } \\
\cline { 2 - 3 } $\boldsymbol{g}$ & \multicolumn{1}{c}{$\begin{array}{c}\text { Lower } \\
\text { limit }\end{array}$} & $\begin{array}{c}\text { Upper } \\
\text { limit }\end{array}$ \\
-0.201 & -0.528 & 0.126 \\
-0.222 & -0.587 & 0.142 \\
0.326 & -0.321 & 0.973 \\
0.571 & -0.116 & 1.258 \\
0.194 & -0.320 & 0.708 \\
0.386 & -0.143 & 0.915 \\
-0.072 & -0.467 & 0.324 \\
0.284 & 0.053 & 0.514 \\
0.541 & -0.152 & 1.234 \\
0.220 & -0.430 & 0.870 \\
0.783 & 0.038 & 1.527 \\
0.752 & -0.037 & 1.541 \\
0.332 & -0.375 & 1.039 \\
0.223 & -0.472 & 0.918 \\
0.196 & 0.029 & 0.364
\end{tabular}

$P$ value
.229
.231
.324
.103
.459
.153
.723
.016
.126
.507
.039
.062
.357
.529
.022

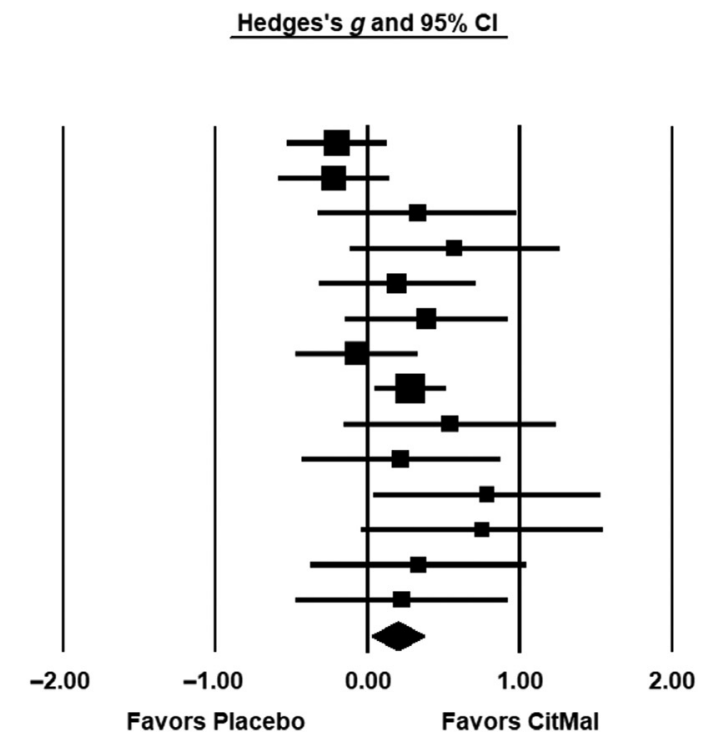

Figure 2 - Forest plot from the main analysis presented as standardized mean difference with the respective $95 \%$ CI, where the size of the squares reflects the statistical weight of each study. CitMal= citrulline malate; $\mathrm{CI}=$ confidence interval. 


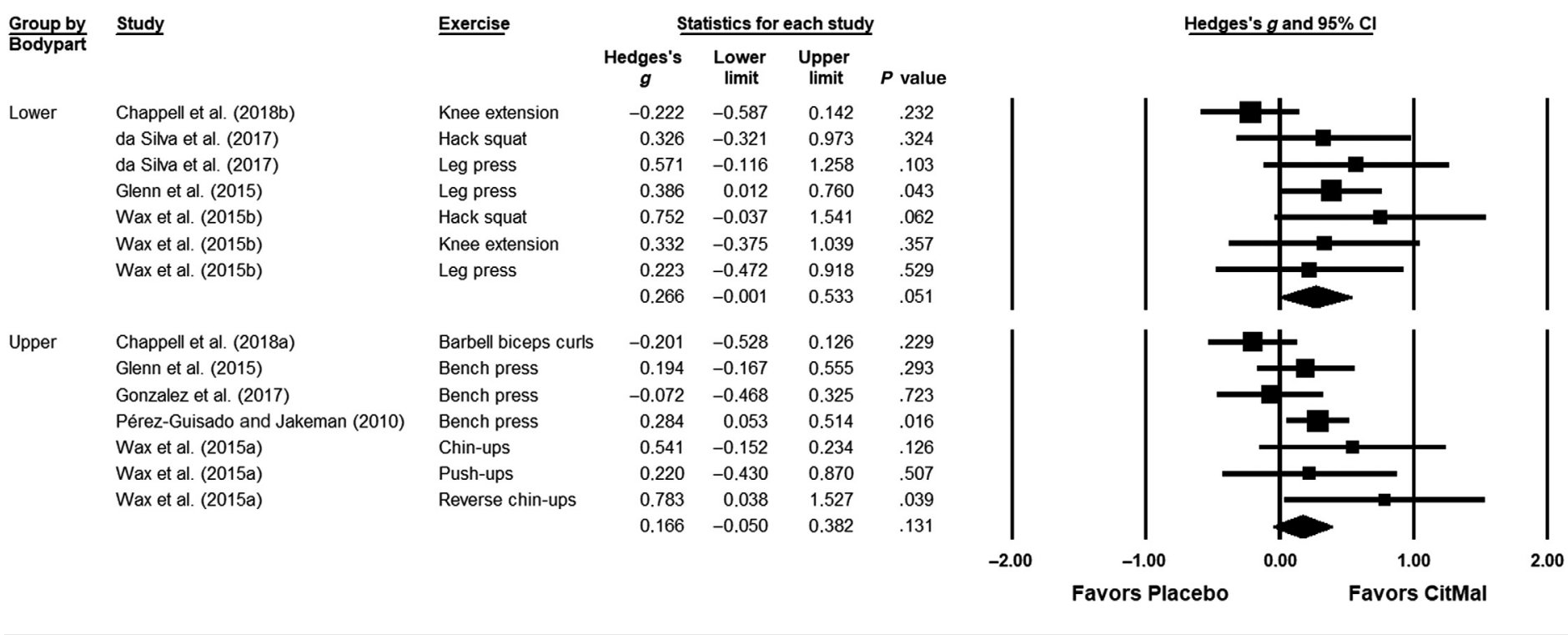

Figure 3 - Forest plot from the subanalysis presented as standardized mean difference with the respective $95 \%$ CI, where the size of the squares reflects the statistical weight of each study. CitMal= citrulline malate; $\mathrm{CI}=$ confidence interval.

supplements on repetitions to failure, such as caffeine (SMD: 0.38; Polito et al., 2016), sodium bicarbonate (SMD: 0.37; Grgic et al., 2020), or long-term use of creatine (14\%; Rawson \& Volek, 2003), but similar to the effect of short-term beta-alanine supplementation on anaerobic performance (SMD: 0.18; Saunders et al., 2016).

Although an overall effect was found for CitMal in the current analysis, the included individual studies showed inconsistent results and require closer scrutiny. Interestingly, the majority of studies employing three to eight sets reported a performance effect of CitMal during multijoint exercises (Glenn et al., 2015; PérezGuisado \& Jakeman, 2010; Wax et al., 2015a, 2015b). However, a performance enhancing effect was not observed during 10 sets of unilateral knee extensions or barbell curls to failure in the studies by Chappell et al. (2018a, 2018b). The lack of benefit may have been impacted by a lack of familiarization with the isokinetic single-leg knee extension machine (Chappell et al., 2018a) and the use of single-joint exercises (Chappell et al., 2018a, 2018b). The possible discrepancies between single joint versus multijoint are intriguing. Although there was a significant effect of CitMal on knee extension repetitions to failure in Wax et al. (2015b), the exercise was performed after two multijoint exercises, whereas participants in Chappell's studies performed only single-joint exercises (Chappell et al., 2018a, 2018b). One could speculate that CitMal's performance effect is greater when multijoint and bilateral exercises are performed due to a greater amount of activated musculature requiring more blood flow and energy production. In support of this, the subanalysis for the lower body resulted in a tendency for a performance effect of CitMal, whereas the upper body analysis observed no effect. Muscles in the lower body have a larger volume than muscles in the upper body (Holzbaur et al., 2007; Lube et al., 2016). Interestingly, the performance effect during upper body exercises in Pérez-Guisado and Jakeman (2010) and Glenn et al. (2015) appeared to be more pronounced in the latter sets of exercise. However, such a trend did not seem to be displayed in other studies employing upper body exercises (Chappell et al., 2018b; Gonzalez et al., 2017; Wax et al., $2015 b)$. Therefore, it is still unclear whether the effect of CitMal is larger in early versus later sets during strength training.
In contrast to the majority of the included studies (Glenn et al., 2015; Pérez-Guisado \& Jakeman, 2010; Wax et al., 2015a, 2015b), da Silva et al. (2017) and Gonzalez et al. (2017) did not observe any effect of CitMal during multijoint exercises. However, the study design by da Silva et al. (2017) was intended to explore CitMal's effect on recovery and performance after a previous workout that aimed to induce markers of muscle damage (i.e., creatine kinase). Therefore, one could speculate whether the lack of a performance enhancing effect of CitMal was attributed to a state of impaired muscle function prior to testing. In addition, da Silva et al. (2017) was the only study that included untrained participants, whereas all other studies investigated the effect of CitMal in strength-trained individuals. Finally, the dosage of CitMal was also lower than the other included studies (6 vs. $8 \mathrm{~g}$ ), which may not have been sufficient to yield a performance effect. It is unclear why CitMal supplementation failed to improve repetition performance in the study by Gonzalez et al. (2017). Notably, the timing of supplement ingestion differed between Gonzalez et al. (2017) and the other included studies (40- vs. 60-min prior to exercise, respectively). Peak plasma arginine concentrations have been shown to occur as late as approximately 90-100 min after oral ingestion with 5-10 g of L-citrulline (Moinard et al., 2008). Thus, 40-min prior to exercise may not be sufficient time for CitMal to exert a performanceenhancing effect. Indeed, it remains unclear whether 60-min prior to exercise is necessarily optimal based upon pharmacokinetic studies. To date, no study has investigated the timing effect of CitMal, and only one article, in which participants ingested Lcitrulline (6 g) or placebo 1 -hr versus 2 -hr before exercise, has compared the timing effects of L-citrulline supplementation (Cutrufello et al., 2015). Although the supplement also contained carbohydrates, neither of the conditions improved chest-press repetitions to failure, $\mathrm{VO}_{2} \mathrm{max}$, anaerobic threshold, or flow-mediated vasodilation. Thus, more research is needed to elucidate whether there is an optimal timing effect of L-citrulline or CitMal prior to exercise.

When evaluating whether CitMal supplementation may enhance repetitions to failure, understanding the mechanisms of action is crucial, yet they are not well understood. Several 
mechanistic factors have been suggested to potentially aid in exercise performance. The anti-fatigue effects allowing for the completion of additional repetitions at a given workload may be explained by a greater oxygen uptake and supply of nutrients to the muscles (Bailey et al., 2012), better buffering capacity (PérezGuisado \& Jakeman, 2010), enhanced calcium handling, lower cost of ATP production (Bailey et al., 2012), improved mitochondrial efficiency (Campos et al., 2018), improved peak force output, and an enhanced muscle efficiency for a given force production (Bailey et al., 2012). Citrulline supplements have also been suggested to significantly reduce subjective ratings of perceived exertion and muscle soreness after exercise (Rhim et al., 2020). The impact of malate is largely unknown as it has not been studied in isolation. However, malate has been proposed to increase oxidative ATP production via the tricarboxylic acid cycle (Bendahan et al., 2002). It remains unclear whether the effects of CitMal are due predominantly to L-citrulline or malate or a synergistic effect. It is also unclear whether a greater dose of CitMal would offer any added benefit as only acute $6-8 \mathrm{~g}$ boluses have been studied. Interestingly, doses up to $10 \mathrm{~g}$ L-citrulline have been shown to be well tolerated and increase plasma arginine concentrations in a dose-response fashion (Moinard et al., 2008). Therefore, researchers should consider investigating higher doses of L-citrulline or CitMal to determine the dosing effects on strength training performance outcomes.

The findings of this review lend support to the notion that CitMal may improve resistance to fatigue, allowing an athlete to increase the amount of work performed over a series of sets, which thereby, may improve the anabolic stimulus and subsequent adaptation to strength training (Schoenfeld et al., 2017). That is, a greater number of repetitions at a given load or more work within each respective set may, over time, contribute to greater strength and hypertrophy outcomes. However, acute improvements in performance do not necessarily translate to an enhanced long-term adaptation. The chronic effects of CitMal supplementation on training-induced gains in muscle strength and hypertrophy have not been extensively investigated, and more research is warranted. Notably, CitMal may play a role in stimulating muscle protein synthesis (Goron et al., 2019), and NO may stimulate satellite cell differentiation (Anderson, 2000).

\section{Side Effects Associated With CitMal Supplementation}

Five of the included studies reported potential adverse events (Chappell et al., 2018a; da Silva et al., 2017; Glenn et al., 2015; Pérez-Guisado \& Jakeman, 2010; Wax et al., 2015b), whereas the remaining three studies did not (Chappell et al., 2018b; Gonzalez et al., 2017; Wax et al., 2015a). Glenn et al. (2015) reported that one participant experienced stomach discomfort after supplementation. However, the same participant reported a similar response during the placebo trial, and therefore, the discomfort may have been attributed to the dextrose and/or artificial flavoring. PérezGuisado and Jakeman (2010) stated that six out of 41 (15\%) participants reported stomach discomfort following CitMal supplementation, whereas no participants in the trials by Wax et al. (2015b) and Chappell et al. (2018a) reported any side effects.

\section{Methodological Quality and Risk of Bias}

Study quality was assessed through the use of the TESTEX score system, which allows for identification of potential discrepancies between studies. All included studies had a score of nine or 10 out of 11 (depicted in Table 2), indicating a high quality. The shortcoming throughout the studies was a lack of reporting for randomization method and adverse events. In addition, only one of the included studies (Glenn et al., 2015) examined the effectiveness of the blinding by asking participants to indicate which trials were the placebo condition and the CitMal condition. In this study, accurate guesses for the trials were only $53 \%$ (not significant); thus, participants were not able to identify the study treatments correctly, rendering no influence on the results. If participants were able to correctly identify the CitMal condition in other studies, it could have influenced the outcome (Hurst et al., 2020). Furthermore, all studies except one (Pérez-Guisado \& Jakeman, 2010) specified that a counterbalanced method was employed to avoid a treatment order effect.

According to the Cochran's $Q$ test and Eggers test for funnel plot asymmetry, there was a tendency for heterogeneity and potential publication bias present, respectively. In addition, Duval and Tweedie's trim and fill analysis method revealed significant funnel plot asymmetry. After adding imputed missing studies, the SMD was adjusted to a nonsignificant SMD of $0.104[-0.017$, 0.216]. Therefore, the current results should be interpreted with caution.

\section{Strengths and Limitations}

The main strengths for the current review and meta-analysis are the use of a systematic search in two databases, following PRISMA guidelines, and assessing study quality with the TESTEX score system. The TESTEX score system is a validated, reliable tool for exercise science studies (Smart et al., 2015). However, it does not contain tools to critically evaluate the quality of research on sports nutrition and supplementation. Notably, several of the included studies did not test to verify the quality/quantity of the CitMal supplement used in the study $(n=5)$. One study (da Silva et al., 2017) analyzed and confirmed the purity of the supplement, whereas analysis in two studies reported a lower content than displayed on the label (Chappell et al., 2018a, 2018b). In addition, none of the included studies measured blood or muscle concentrations of citrulline, arginine, or nitrite, making it difficult to confirm the suggested mechanisms of CitMal. Thus, additional original work is required to explore basic physiological aspects of the supplement.

Other limitations of this review and meta-analysis are that few studies are available on the topic, which decreased statistical power —in particular for the subanalyses. It has been suggested that a minimum of five studies is sufficient to achieve adequate statistical power in a meta-analysis (Jackson \& Turner, 2017); however, this also depends on sample size and statistical power within each included study. In addition, only $26(\sim 19 \%)$ of 137 participants were females; therefore, one cannot draw any conclusions regarding potential sex differences. Although the main analysis was conducted with each individual exercise tested, it was conducted in a conservative approach with no double counting of studies. In addition, sensitivity analyses revealed that the results were quite robust, and only removal of the study by Pérez-Guisado and Jakeman (2010) would result in a nonsignificant finding $(p=.052)$, although with a small impact on the SMD (0.196-0.189). Nevertheless, inconsistent results in the included studies warrant more research on the topic of CitMal before any compelling conclusion can be drawn. 


\section{Conclusion and Perspectives}

The current analysis revealed a small ergogenic effect on number of repetitions to failure with acute CitMal supplementation, resulting in a weighted percentage difference of $6.4 \pm 7.9 \%$ (SMD: 0.196) compared with placebo. Although the lower body subanalysis revealed a tendency for an effect of CitMal $(8.1 \pm 8.4 \%)$, no significant difference was noted for the upper body $(5.7 \pm 8.4 \%)$. The supplement may, therefore, lead to a small but potentially meaningful ergogenic performance effect during resistance exercise. More CitMal research is needed to elucidate the acute effects on strength training performance and the long-term effects on neuromuscular adaptations.

\section{Acknowledgments}

The study was designed by F.T. Vårvik, T. Bjørnsen, and A.M. Gonzalez; data were collected by T. Bjørnsen and F.T. Vårvik and analyzed by F.T. Vårvik; data interpretation, manuscript preparation, and revisions were undertaken by F.T. Vårvik, T. Bjørnsen, and A.M. Gonzalez. All authors approved the final version of the article. A.M. Gonzalez declares that he serves as the Scientific Advisor for Shifted, a manufacturer of sports supplements; however, the preparation of this manuscript was completed prior to initiating this role. All other authors declare no conflicts of interest. No funding was received in relation to the present article.

\section{References}

Anderson, J.E. (2000). A role for nitric oxide in muscle repair: Nitric oxide-mediated activation of muscle satellite cells. Molecular Biology of the Cell, 11(5), 1859-1874. PubMed ID: 10793157 doi:10.1091/ mbc.11.5.1859

Bahadoran, Z., Mirmiran, P., Kashfi, K., \& Ghasemi, A. (2020). Endogenous flux of nitric oxide: Citrulline is preferred to Arginine. Acta Physiologica, 231(3), e13572. PubMed ID: 33089645 doi:10.1111/ apha.13572

Bailey, S.J., Vanhatalo, A., Winyard, P.G., \& Jones, A.M. (2012). The nitrate-nitrite-nitric oxide pathway: Its role in human exercise physiology. European Journal of Sport Science, 12(4), 309-320. doi:10. 1080/17461391.2011.635705

Bendahan, D., Mattei, J.P., Ghattas, B., Confort-Gouny, S., Le Guern, M.E., \& Cozzone, P.J. (2002). Citrulline/malate promotes aerobic energy production in human exercising muscle. British Journal of Sports Medicine, 36(4), 282-289. PubMed ID: 12145119 doi:10. $1136 / \mathrm{bjsm} .36 .4 .282$

Borenstein, M. (Ed.). (2009). Introduction to meta-analysis. John Wiley \& Sons.

Borenstein, M., Hedges, L.V., Higgins, J.P.T., \& Rothstein, H.R. (2009). Multiple outcomes or time-points within a study. In M. Borenstein (Ed.), Introduction to meta-analysis (pp. 225-238). John Wiley \& Sons, Ltd.

Calbet, J.A.L., Gonzalez-Alonso, J., Helge, J.W., Søndergaard, H., Munch-Andersen, T., Boushel, R., \& Saltin, B. (2007). Cardiac output and leg and arm blood flow during incremental exercise to exhaustion on the cycle ergometer. Journal of Applied Physiology, 103(3), 969978. PubMed ID: 17600155 doi:10.1152/japplphysiol.01281.2006

Campos, H.O., Drummond, L.R., Rodrigues, Q.T., Machado, F.S.M., Pires, W., Wanner, S.P., \& Coimbra, C.C. (2018). Nitrate supplementation improves physical performance specifically in non-athletes during prolonged open-ended tests: A systematic review and metaanalysis. British Journal of Nutrition, 119(6), 636-657. PubMed ID: 29553034 doi:10.1017/S0007114518000132
Chappell, A.J., Allwood, D.M., Johns, R., Brown, S., Sultana, K., Anand, A., \& Simper, T. (2018a). Citrulline malate supplementation does not improve German Volume Training performance or reduce muscle soreness in moderately trained males and females. Journal of the International Society of Sports Nutrition, 15(1), 42. doi:10.1186/ s12970-018-0245-8

Chappell, A.J., Allwood, D.M., \& Simper, T.N. (2018b). Citrulline malate fails to improve German volume training performance in healthy young men and women. Journal of Dietary Supplements. 2020;17(3): 249-260.

Cohen, J. (1988). Statistical power analysis for the behavioral sciences (2nd ed.). New York, NY: Lawrence Erlbaum Associates.

Cunniffe, B., Papageorgiou, M., O’Brien, B., Davies, N.A., Grimble, G.K., \& Cardinale, M. (2016). Acute citrulline-malate supplementation and high-intensity cycling performance. Journal of Strength and Conditioning Research, 30(9), 2638-2647. PubMed ID: 26808848 doi:10. 1519/JSC.0000000000001338

Cutrufello, P.T., Gadomski, S.J., \& Zavorsky, G.S. (2015). The effect of L-citrulline and watermelon juice supplementation on anaerobic and aerobic exercise performance. Journal of Sports Sciences, 33(14), 1459-1466. PubMed ID: 25517106 doi:10.1080/02640414.2014. 990495

da Silva, D.K., Jacinto, J.L., de Andrade, W.B., Roveratti, M.C., Estoche, J.M., Balvedi, M.C.W... Aguiar, A.F. (2017). Citrulline malate does not improve muscle recovery after resistance exercise in untrained young adult men. Nutrients, 9(10), 1132. doi:10.3390/ nu9101132

Farney, T.M., Bliss, M.V., Hearon, C.M., \& Salazar, D.A. (2017). The effect of citrulline malate supplementation on muscle fatigue among healthy participants. Journal of Strength and Conditioning Research, 33(9), 2464-2470. doi:10.1519/JSC.0000000000002356

Figueroa, A., Wong, A., Jaime, S.J., \& Gonzales, J.U. (2017). Influence of L-citrulline and watermelon supplementation on vascular function and exercise performance. Current Opinion in Clinical Nutrition and Metabolic Care, 20(1), 92-98. PubMed ID: 27749691 doi:10.1097/ MCO.0000000000000340

Glenn, J.M., Gray, M., Jensen, A., Stone, M.S., \& Vincenzo, J.L. (2016). Acute citrulline-malate supplementation improves maximal strength and anaerobic power in female, masters athletes tennis players. European Journal of Sport Science, 16(8), 1095-1103. PubMed ID: 27017895 doi:10.1080/17461391.2016.1158321

Glenn, J.M., Gray, M., Wethington, L.N., Stone, M.S., Stewart, R.W., \& Moyen, N.E. (2015). Acute citrulline malate supplementation improves upper- and lower-body submaximal weightlifting exercise performance in resistance-trained females. European Journal of Nutrition, 56(2), 775-784. PubMed ID: 26658899 doi:10.1007/ s00394-015-1124-6

Gonzalez, A.M., Spitz, R.W., Ghigiarelli, J.J., Sell, K.M., \& Mangine, G.T. (2017). Acute effect of citrulline malate supplementation on upper-body resistance exercise performance in recreationally resistance-trained men. Journal of Strength and Conditioning Research, 32(11), 3088-3094. doi:10.1519/JSC.0000000000002373

Gonzalez, A.M., \& Trexler, E.T. (2020). Effects of citrulline supplementation on exercise performance in humans: A review of the current literature. Journal of Strength and Conditioning Research, 34(5), 1480-1495. PubMed ID: 31977835 doi:10.1519/JSC.00000000 00003426

Goron, A., Lamarche, F., Blanchet, S., Delangle, P., Schlattner, U., Fontaine, E., \& Moinard, C. (2019). Citrulline stimulates muscle protein synthesis, by reallocating ATP consumption to muscle protein synthesis. Journal of Cachexia, Sarcopenia and Muscle, 10(4), 919-928. PubMed ID: 31070021 doi:10.1002/jcsm.12435 
Grgic, J., Rodriguez, R.F., Garofolini, A., Saunders, B., Bishop, D.J., Schoenfeld, B.J., \& Pedisic, Z. (2020). Effects of sodium bicarbonate supplementation on muscular strength and endurance: A systematic review and meta-analysis. Sports Medicine, 50(7), 1361-1375. PubMed ID: 32096113 doi:10.1007/s40279-020-01275-y

Higgins, J., \& Green, S. (2009). Cochrane handbook for systematic reviews of interventions (Vol. 5). The Cochrane Collaboration.

Holzbaur, K.R.S., Murray, W.M., Gold, G.E., \& Delp, S.L. (2007). Upper limb muscle volumes in adult subjects. Journal of Biomechanics, 40(4), 742-749. PubMed ID: 17241636 doi:10.1016/j.jbiomech. 2006.11.011

Hurst, P., Schipof-Godart, L., Szabo, A., Raglin, J., Hettinga, F., Roelands, B.... Beedie, C. (2020). The Placebo and Nocebo effect on sports performance: A systematic review. European Journal of Sport Science, 20(3), 279-292. PubMed ID: 31414966 doi:10.1080/ 17461391.2019 .1655098

Jackson, D., \& Turner, R. (2017). Power analysis for random-effects metaanalysis. Research Synthesis Methods, 8(3), 290-302. PubMed ID: 28378395 doi:10.1002/jrsm.1240

Jagim, A.R., Harty, P.S., \& Camic, C.L. (2019). Common ingredient profiles of multi-ingredient pre-workout supplements. Nutrients, 11(2), 254. doi:10.3390/nu11020254.

Lube, J., Cotofana, S., Bechmann, I., Milani, T.L., Özkurtul, O., Sakai, T.... Hammer, N. (2016). Reference data on muscle volumes of healthy human pelvis and lower extremity muscles: An in vivo magnetic resonance imaging feasibility study. Surgical and Radiologic Anatomy, 38(1), 97-106. PubMed ID: 26251021 doi:10.1007/ s00276-015-1526-4

Martínez-Sánchez, A., Alacid, F., Rubio-Arias, J.A., Fernández-Lobato, B., Ramos-Campo, D.J., \& Aguayo, E. (2017). Consumption of watermelon juice enriched in L-citrulline and pomegranate ellagitannins enhanced metabolism during physical exercise. Journal of Agricultural and Food Chemistry, 65(22), 4395-4404. PubMed ID: 28513179 doi:10.1021/acs.jafc.7b00586

Maughan, R.J., Burke, L.M., Dvorak, J., Larson-Meyer, D.E., Peeling, P., Phillips, S.M., Rawson, E.S., ... Engebretsen, L. (2018). IOC consensus statement: Dietary supplements and the high-performance athlete. British Journal of Sports Medicine, 52(7), 439-455. PubMed ID: 29540367 doi:10.1136/bjsports-2018-099027

Moher, D., Liberati, A., Tetzlaff, J., Altman, D.G., \& The PRISMA Group. (2009). Preferred reporting items for systematic reviews and metaanalyses: The PRISMA statement. PLoS Medicine, 6(7), e1000097. PubMed ID: 19621072 doi:10.1371/journal.pmed.1000097

Moinard, C., Nicolis, I., Neveux, N., Darquy, S., Bénazeth, S., \& Cynober, L. (2008). Dose-ranging effects of citrulline administration on plasma amino acids and hormonal patterns in healthy subjects: The Citrudose pharmacokinetic study. British Journal of Nutrition, 99(4), 855-862. PubMed ID: 17953788 doi:10.1017/S0007114507841110

Nunes, J.P., Grgic, J., Cunha, P.M., Ribeiro, A.S., Schoenfeld, B.J., de Salles, B.F., \& Cyrino, E.S. (2020). What influence does resistance exercise order have on muscular strength gains and muscle hypertrophy? A systematic review and meta-analysis. European Journal of Sport Science, 1-9. doi:10.1080/17461391.2020.1733672

Pérez-Guisado, J., \& Jakeman, P.M. (2010). Citrulline malate enhances athletic anaerobic performance and relieves muscle soreness. Journal of Strength and Conditioning Research, 24(5), 1215-1222. doi:10. 1519/JSC.0b013e3181cb28e0
Polito, M.D., Souza, D.B., Casonatto, J., \& Farinatti, P. (2016). Acute effect of caffeine consumption on isotonic muscular strength and endurance: A systematic review and meta-analysis. Science \& Sports, 31(3), 119-128. doi:10.1016/j.scispo.2016.01.006

Rawson, E.S., \& Volek, J.S. (2003). Effects of creatine supplementation and resistance training on muscle strength and weightlifting performance. Journal of Strength and Conditioning Research, 17(4), 822-831.

Rhim, H.C., Kim, S., Park, J., \& Jang, K.-M. (2020). Effect of citrulline on post-exercise rating of perceived exertion, muscle soreness, and blood lactate levels: A systematic review and meta-analysis. Journal of Sport and Health Science, 9(6), 1-9. doi:10.1016/j. jshs.2020.02.003

Saunders, B., Elliott-Sale, K., Artioli, G.G., Swinton, P.A., Dolan, E., Roschel, H. ... Gualano, B. (2016). $\beta$-Alanine supplementation to improve exercise capacity and performance: A systematic review and meta-analysis. British Journal of Sports Medicine, 51(8), 658-669. PubMed ID: 27797728 doi:10.1136/bjsports-2016-096396

Schoenfeld, B.J., Ogborn, D., \& Krieger, J.W. (2017). Dose-response relationship between weekly resistance training volume and increases in muscle mass: A systematic review and meta-analysis. Journal of Sports Sciences, 35(11), 1073-1082. PubMed ID: 27433992 doi: 10.1080/02640414.2016.1210197

Schwedhelm, E., Maas, R., Freese, R., Jung, D., Lukacs, Z., Jambrecina, A., ... Böger, R.H. (2008). Pharmacokinetic and pharmacodynamic properties of oral L-citrulline and L-arginine: Impact on nitric oxide metabolism. British Journal of Clinical Pharmacology, 65(1), 51-59. PubMed ID: 17662090 doi:10.1111/j.1365-2125.2007.02990.x

Smart, N.A., Waldron, M., Ismail, H., Giallauria, F., Vigorito, C., Cornelissen, V., \& Dieberg, G. (2015). Validation of a new tool for the assessment of study quality and reporting in exercise training studies: TESTEX. International Journal of Evidence-Based Healthcare, 13(1), 9-18. PubMed ID: 25734864 doi:10.1097/XEB. 0000000000000020

Stamler, J.S., \& Meissner, G. (2001). Physiology of nitric oxide in skeletal muscle. Physiological Reviews, 81(1), 209-237. PubMed ID: 11152758 doi:10.1152/physrev.2001.81.1.209

Trexler, E.T., Keith, D.S., Schwartz, T.A., Ryan, E.D., Stoner, L., Persky, A.M., \& Smith-Ryan, A.E. (2019a). Effects of citrulline malate and beetroot juice supplementation on blood flow, energy metabolism, and performance during maximum effort leg extension exercise. Journal of Strength and Conditioning Research, 33(9), 2321-2329. doi:10.1519/JSC.0000000000003286

Trexler, E.T., Persky, A.M., Ryan, E.D., Schwartz, T.A., Stoner, L., \& Smith-Ryan, A.E. (2019b). Acute effects of citrulline supplementation on high-intensity strength and power performance: A systematic review and meta-analysis. Sports Medicine, 49(5), 707-718. PubMed ID: 30895562 doi:10.1007/s40279-019-01091-z

Wax, B., Kavazis, A.N., \& Luckett, W. (2015a). Effects of supplemental citrulline-malate ingestion on blood lactate, cardiovascular dynamics, and resistance exercise performance in trained males. Journal of Dietary Supplements, 13(3), 269-282. PubMed ID: 25674699 doi: $10.3109 / 19390211.2015 .1008615$

Wax, B., Kavazis, A.N., Weldon, K., \& Sperlak, J. (2015b). Effects of supplemental citrulline malate ingestion during repeated bouts of lower-body exercise in advanced weightlifters. Journal of Strength and Conditioning Research, 29(3), 786-792. PubMed ID: 25226311 doi:10.1519/JSC.0000000000000670 